Note

\section{Productivity of Pyrichalasin H, a Phytotoxic Metabolite, from Different Isolates of Pyricularia grisea and from Other Isolates of Pyricularia spp.}

\author{
Manabu Nukina and Tsuneo Nama** \\ Department of Agricultural Chemistry, \\ * Department of Agriculture, Faculty of Agriculture, \\ Yamagata University, Tsuruoka 997, Japan
}

Received January 17, 1991

Pyrichalasin $\mathrm{H}$ has been isolated as a phytotoxic metabolite from Pyricularia grisea (IFO 7287), a causative fungus of blast disease in crabgrass, Digitaria sanguinalis. ${ }^{1)}$
Pyrichalasin $\mathrm{H}$ belongs to a family of the cytochalasan class of fungal metabolite, which shows various unique biological properties. ${ }^{2)}$ Previously identified metabolites produced by Pyricularia spp. include pyriculol, ${ }^{3)}$ pyriculariol, ${ }^{4)}$ tenuazonic acid, ${ }^{5)}$ terrestric acid ${ }^{6)}$ and p-hydroxyphenylethanol, ${ }^{7)}$ as well as some others. ${ }^{8)}$ The genus Pyricularia contains rice blast fungus $P$. oryzae as an agriculturally important pathogen. Many isolates from various cultivars of rice plants can be separated into pathogenically different races. We have been studying the relationship between the productivity of this secondary metabolite and the fungal species of the genus Pyricularia. In this paper, we report that all isolates obtained from blast lesions of crabgrass collected from different locations in Japan during 1990 produced pyrichalasin $\mathrm{H}$, and also a dihydro derivative ${ }^{9)}$ of pyriculol, 2-(3,4-dihydroxyhepta1,5-dienyl)-6-hydroxybenzyl alcohol. The latter compound, abbreviated as dihydropyriculol in this paper, has previously been isolated from Pyricularia oryzae. ${ }^{9)}$ We also report that isolates from Italian ryegrass and Manchurian wild rice were also found to produce pyrichalasin $\mathbf{H}$ and dihydropyriculol, while the isolates from rice and green
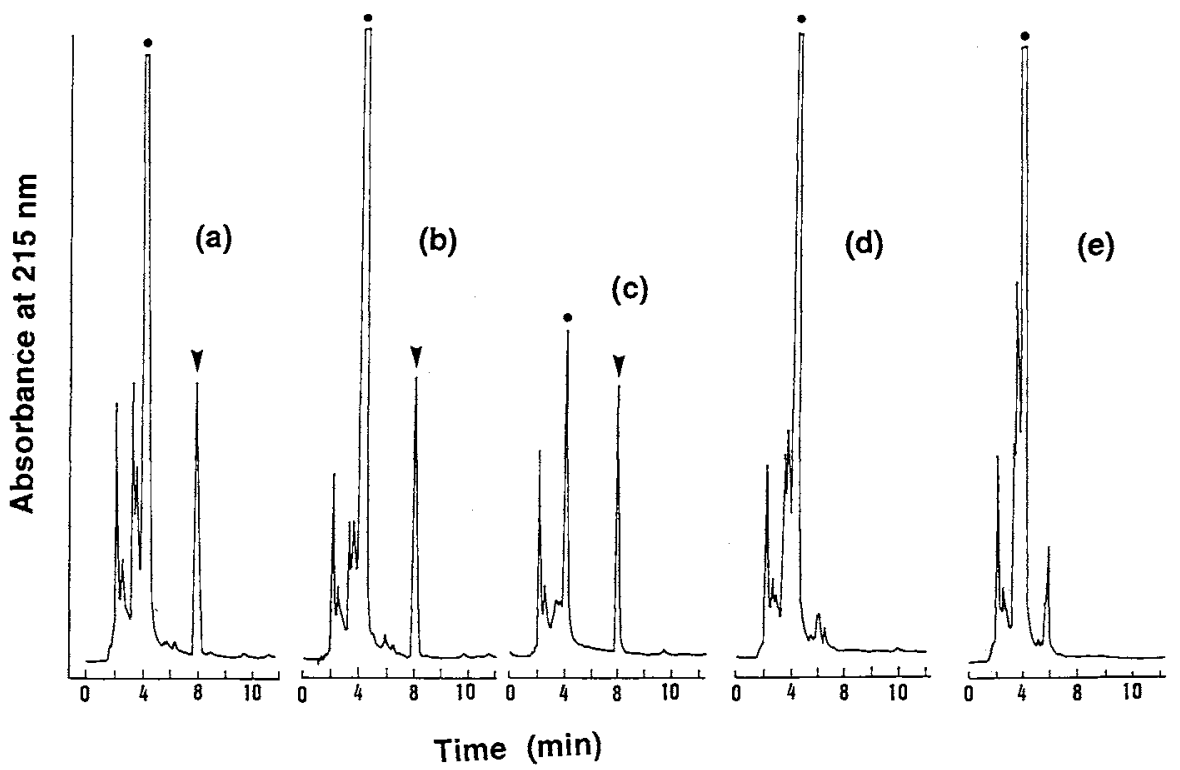

Fig. 1. HPLC Profiles of Extracts from Culture Filtrates of Pyricularia Isolates from Different Host Plants.

(a) Typical pattern of the isolate from crabgrass.

(b) Isolate from Italian ryegrass.

(c) Isolate from Manchurian wild rice.

(d) Isolate from rice.

(e) Isolate from green bristlegrass.

The markers for the peaks indicate the corresponding compounds, i.e., $\bullet=$ dihydropyriculol, $\mathbf{Y}=$ pyrichalasin $H$. These chromatograms were obtained by injecting a 5 - $\mu$ l portion of each of the respective methanol eluates. From an analysis of these chromatograms and appropriate dilution experiments, pyrichalasin $\mathrm{H}$ was detected in amounts of $0.8 \mu \mathrm{g}, 0.7 \mu \mathrm{g}$ and $0.6 \mu \mathrm{g}$ in (a), (b) and (c), respectively. Dihydropyriculol was detected in amounts of $6 \mu \mathrm{g}, 7 \mu \mathrm{g}, 0.1 \mu \mathrm{g}, 3 \mu \mathrm{g}$ and $8 \mu \mathrm{g}$ in (a), (b), (c), (d) and (e), respectively. 
bristlegrass were found not to produce pyrichalasin $\mathrm{H}$, but did produce dihydropyriculol.

A total of 75 isolates were obtained from blast lesions of crabgrass collected at 41 sites in 24 prefectures $^{10)}$ in 1990. All these isolates were obtained by a single spore isolation. In Yamagata prefecture, several isolates were also obtained from blast lesions of rice (Oryza sativa), Italian ryegrass (Lolium multiflorum), Manchurian wild rice (Zizania latifolia) and green bristlegrass (Setaria viridis). These isolates were cultured in a soy sauce-sucrose medium $^{11)}$ (commercial soy sauce $(50 \mathrm{ml}$ ) and sucrose $(50 \mathrm{mg})$ in 11 of tap water; $100 \mathrm{ml}$ of this medium was used in a $500-\mathrm{ml}$ Sakaguchi flask) by shaking at $25-28^{\circ} \mathrm{C}$ in darkness for 10 days. The cultivation period for the isolates of Manchurian wild rice was 17 days. After cultivating, each culture medium was filtered through filter paper. Each mycelial sample was dried to measure the dry weight, which was in the range of $1.2-2.3 \mathrm{~g}$. A part ( $2 \mathrm{ml})$ of each culture filtrate adjusted in volume to $100 \mathrm{ml}$ was passed through a Sep-Pak cartridge of $\mathrm{C}_{18}$ (Waters) and eluted with methanol. Each methanol eluate was analyzed by high-performance liquid chromatography (HPLC, Nucleosil-ODS-5; MeOH: $\mathrm{H}_{2} \mathrm{O}=7: 3$; flow rate, $1.0 \mathrm{ml} / \mathrm{min}$; detection, UV at $215 \mathrm{~nm}$; retention time for pyrichalasin $\mathrm{H}, 8.4 \mathrm{~min}$; for dihydropyriculol, $4.4 \mathrm{~min}$ ) and thin-layer chromatography (Kieselgel $60 \mathrm{~F}_{254}$ (Merck), $\mathrm{CHCl}_{3}$ : $\mathrm{MeOH}=10: 1$; pyrichalasin $\mathrm{H}, R f=0.56$; dihydropyriculol, $R f=0.22$ ). The identification of these compounds was carried out by comparing with authentic samples regarding the chromatographic mobility in different solvent system, including co-injection experiments. Figure 1 shows typical HPLC profiles. Pyrichalasin $\mathrm{H}$ was detected in all culture filtrates of the isolates from crabgrass, even though collected from different locations. Thus, pyrichalasin $\mathbf{H}$ productivity may be used as a physiological marker to distinguish the origins of host plants of Pyricularia species. Analyses of the metabolites produced by isolates from rice, Italian ryegrass, Manchurian wild rice and green bristlegrass revealed that pyrichalasin $\mathrm{H}$ was also produced by the isolates from Italian ryegrass and Manchurian wild rice as shown in Fig. 1. With respect to the fungal morphological appearance among these isolates, that from Manchurian wild rice was very different from the other isolates of the different host plants. The isolates from Manchurian wild rice formed white mycelium after cultivating under the stated conditions, and their fungal growth was very slow compared to that of the other isolates from different host plants. Spores of the Manchurian wild rice isolates were bigger than those of the other isolates. Although this morphological difference existed, the fact that they each produced pyrichalasin $\mathrm{H}$ and dihydropyriculol is interesting from the chemotaxonomical viewpoint. The production of dihydropyriculol was observed in all isolates, regardless of the host plants used in this study. Dihydropyriculol productivity may be used as a chemotaxonomical marker for certain species belonging to the genus Pyricularia. Although it should be noted that some isolates maintained in our laboratory could not produce pyrichalasin $\mathrm{H}$ and/or dihydropyriculol, all the isolates from crabgrass, when cultured immediately after isolating from diseased leaves, always produced these metabolites.

Acknowledgment. The authors thank the following people for collecting diseased plants from different locations: N. Sato, K. Oota, T. Takahashi, H. Nakaminami, H. Kudo, H. Ito, K. Furukawa, M. Yusa, M. Sato, K. Fushimi, H. Koga, N. Sakuma, T. Yoshino, H. Takenaka, Z. Ike, K. Murakami, T. Yagi, K. Nasuda, M. Ono, Y. Ando, H. Saito, T. Fujimoto, S. Horiuchi, K. Takeda, Y. Kashima, H. Yamamoto, Y. Yamamoto and H. Matsuoka.

\section{References and Notes}

1) M. Nukina, Agric. Biol. Chem., 51, 2625 (1987).

2) M. Binder and Ch. Tamm, Angew. Chem. Int. Ed. Engl., 12, 370 (1973).

3) S. Iwasaki, S. Nozoe and S. Okuda, Tetrahedron Lett., 1969, 3977; M. Suzuki, T. Sugiyama, M. Watanabe, T. Murayama and K. Yamashita, Agric. Biol. Chem., 51, 1121 (1987).

4) M. Nukina, T. Sassa, M. Ikeda, T. Umezawa and H. Tasaki, Agric. Biol. Chem., 45, 2161 (1981).

5) N. Umetsu, J. Kaji and K. Tamari, Agric. Biol. Chem., 36, 859 (1972); S. Iwasaki, H. Muro, S. Nozoe and S. Okuda, Tetrahedron Lett., 1972, 13; M. H. Lebrun, F. Dutfoy, F. Gaudemer, G. Kunesch and A. Gaudemer, Phytochemistry, 29, 3777 (1990).

6) M. Nukina, Agric. Biol. Chem., 52, 2357 (1988).

7) M. Devys, J. F. Bousquet and M. Barbier, Phytopath. Z., 85, 176 (1976).

8) W. B. Turner and D. C. Aldridge, "Fungal Metabolites II," Academic Press, London, 1983.

9) S. Iwasaki, H. Muro, K. Sasaki, S. Nozoe and S. Okuda, Tetrahedron Lett., 1973, 3537.

10) The names of prefectures and numbers of isolates (in parenthesis) were as follows: Aomori (7), Akita (2), Iwate (6), Yamagata (2), Fukushima (6), Miyagi (4), Tochigi (2), Chiba (1), Gunma (2), Niigata (6), Toyama (2), Ishikawa (6), Fukui (2), Yamanashi (4), Shizuoka (2), Aichi (6), Nagano (2), Gifu (2), Mie (2), Okayama (2), Tottori (2), Kagawa (2), Kouchi (2) and Miyazaki (1).

11) This medium was found to be one of the best for cultivating these fungal isolates by comparing nineteen different media used for fungal culture (M. Nukina, unpublished results). The author (M.N.) found that the addition of soy sauce to a synthetic medium resulted in an increase of fungal growth. 